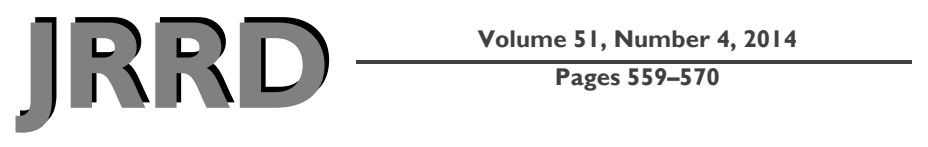

\title{
Pain experience of Iraq and Afghanistan Veterans with comorbid chronic pain and posttraumatic stress
}

\author{
Samantha D. Outcalt, PhD $;{ }^{1-2 *}$ Dennis C. Ang, MD ${ }^{3}{ }^{3}$ ingwei Wu, MS; ${ }^{4}$ Christy Sargent, BA; ${ }^{1}$ Zhangsheng Yu, \\ PhD $;^{4}$ Matthew J. Bair, MD, MS ${ }^{1,5}$ \\ ${ }^{1}$ Department of Veterans Affairs (VA) Center of Excellence on Implementing Evidence-Based Practice, Richard L. \\ Roudebush VA Medical Center, Indianapolis, IN; ${ }^{2}$ Department of Psychiatry, Indiana University School of Medicine, \\ Indianapolis, IN; ${ }^{3}$ Department of Medicine, Wake Forest University School of Medicine, Winston-Salem, NC; \\ ${ }^{4}$ Department of Biostatistics, Indiana University School of Medicine, Indianapolis, IN; ${ }^{5}$ Department of Medicine, Indi- \\ ana University School of Medicine, Indianapolis, IN; and Regenstrief Institute, Inc, Indianapolis, IN
}

\begin{abstract}
Chronic pain and posttraumatic stress disorder (PTSD) co-occur at high rates, and Veterans from recent wars in Iraq and Afghanistan may be particularly vulnerable to both conditions. The objective of this study was to identify key aspects of chronic pain, cognitions, and psychological distress associated with comorbid PTSD among this sample of Veterans. Baseline data were analyzed from a randomized controlled trial testing a stepped-care intervention for chronic musculoskeletal pain. Operation Iraqi Freedom/Operation Enduring Freedom (OIF/OEF) Veterans with chronic pain only $(n=173)$ were compared with those with chronic pain and clinically significant posttraumatic stress symptoms $(n=68)$. Group differences on pain characteristics, pain cognitions, and psychological distress were evaluated. Results demonstrated that OIF/OEF Veterans with comorbid chronic musculoskeletal pain and PTSD experienced higher pain severity, greater painrelated disability and increased pain interference, more maladaptive pain cognitions (e.g., catastrophizing, self-efficacy, pain centrality), and higher affective distress than those with chronic pain alone. Veterans of recent military conflicts in Iraq and Afghanistan may be particularly vulnerable to the compounded adverse effects of chronic pain and PTSD. These results highlight a more intense and disabling pain and psychological experience for those with chronic pain and PTSD than for those without PTSD.
\end{abstract}

Clinical Trial Registration: ClinicalTrials.gov; NCT00386243. "Evaluation of Stepped Care for Chronic Pain in Iraq/Afghanistan Veterans (ESCAPE)"; http://www.clinicaltrails.gov/ct2/show/ NCT00386243.
Key words: chronic pain, cognitions, comorbidity, mental health, musculoskeletal pain, pain severity, posttraumatic stress, trauma, Veterans, Veteran health.

\section{INTRODUCTION}

Chronic pain and posttraumatic stress disorder (PTSD) are significant health problems, especially among military Veterans. A study of Persian Gulf war Veterans documented pain as the most frequently

\footnotetext{
Abbreviations: $\mathrm{ANCOVA}=$ analysis of covariance, $\mathrm{BPI}=$ Brief Pain Inventory, ESCAPE = Evaluation of Stepped Care for Chronic Pain (study), GAD-7 = Generalized Anxiety Disorder, GCPS $=$ Graded Chronic Pain Scale, OEF $=$ Operation Enduring Freedom, OIF = Operation Iraqi Freedom, OND = Operation New Dawn, PCL = Posttraumatic Stress Disorder Checklist, PCL-C $=$ Posttraumatic Stress Disorder ChecklistCivilian, PC-PTSD $=$ Primary Care PTSD screen, PCS $=$ Pain Catastrophizing Scale, PHQ-9 = Patient Health Questionnaire, $\mathrm{PTSD}=$ posttraumatic stress disorder, $\mathrm{SD}=$ standard deviation, VA = Department of Veterans Affairs.

*Address all correspondence to Samantha D. Outcalt, PhD; Roudebush VA Medical Center, 1481 W 10th St (11H), Indianapolis, IN 46202; 317-988-2161; fax: 317-988-3222.

Email: soutcalt@iupui.edu http://dx.doi.org/10.1682/JRRD.2013.06.0134
} 
reported symptom [1]. Lifetime prevalence of PTSD among Vietnam Veterans is 18.7 percent [2], approximately three times higher than the lifetime prevalence rate of 6.8 percent for U.S. adults [3]. Increasingly, the literature is illuminating more about the prevalence, costs, and impact of the comorbidity between these two conditions. In a recent study of Veterans receiving treatment for chronic pain, PTSD was identified in 49 percent of the sample [4]. Among Veterans seeking mental health treatment for PTSD, comorbid chronic pain was diagnosed in 66 percent of the patients studied [5]. The National Comorbidity Survey revealed that musculoskeletal pain was associated with a 400 percent increased risk of developing PTSD [6].

Veterans of more recent wars in Afghanistan and Iraq, collectively referred to as "OIF/OEF/OND" (Operation Iraqi Freedom [OIF]/Operation Enduring Freedom [OEF]/Operation New Dawn [OND]) Veterans, may be particularly vulnerable to experiencing chronic pain and PTSD due to extended and repeated deployments. These multiple tours have often included high-intensity conflicts that result in higher rates of injury and trauma exposure. Pain is a significant clinical condition and PTSD is one of the most common psychiatric diagnoses among this population [7-12]. Although it is known that these are highly prevalent conditions among individuals returning from recent wars, an understanding of the complexity of the chronic pain and PTSD relationship is limited. Importantly, a recent study of Veterans seeking treatment for chronic pain began to untangle this complex relationship. By comparing patients with pain and PTSD with those with pain only, Alschuler and Otis identified notable differences in coping strategies and beliefs about pain [13]. Specifically, their findings suggest that those individuals with comorbid PTSD perceive less control over their pain, hold stronger beliefs that pain is affected by emotions, and catastrophize more about pain.

The current study assessed the physical, functional, and psychological experience of Veterans with comorbid chronic pain and PTSD. The foundation of this study presupposes a biopsychosocial understanding that chronic pain impacts multiple domains and draws from theoretical models of pain-PTSD comorbidity. The study team hypothesized that Veterans with both chronic pain and PTSD, compared with those with chronic pain only, would report a worse overall experience in terms of pain severity, pain-related disability, pain interference, cognitions related to pain, and psychological distress. This study expands upon Alschuler and Otis' work [13] by further exploring the cognitive patterns of Veterans with pain and PTSD. Whereas their study used catastrophizing items that examine only the helplessness feature of the construct, the current project comprehensively investigated all three proposed components of catastrophizing (i.e., rumination, magnification, helplessness) [14]. The current study also examined pain self-efficacy as an important cognition that can affect self-management behavior and pain outcomes. Additionally, this study is the first to include the construct of pain centrality (i.e., thoughts of pain as fundamental to one's life or identity) in an analysis of pain-PTSD comorbidity.

Specifically, compared with Veterans with chronic pain alone, the study team expected to find worsened pain reports (higher pain severity, more pain-related disability, greater pain interference), more maladaptive thoughts related to pain (pain catastrophizing, pain selfefficacy, centrality of pain), and more depression and anxiety symptoms among Veterans with comorbid PTSD. These hypotheses were tested with an overarching aim of better understanding the complex relationship between these two conditions.

\section{METHODS}

\section{Data Source and Procedure}

The study team analyzed baseline data from the Evaluation of Stepped Care for Chronic Pain (ESCAPE) study, a randomized controlled trial designed to test the effectiveness of a stepped care intervention to improve functional and other pain outcomes in OIF/OEF Veterans with chronic musculoskeletal pain. Although the term "OIF/OEF/OND" is now standard for referring to Veterans returning from recent wars in Iraq and Afghanistan, it is important to note that because OND began as the study was drawing to a close, no OND Veterans participated in this study. Veterans of OIF/OEF were eligible for the study if they reported persistent musculoskeletal pain of at least 3 months' duration and their pain was associated with at least moderate functional limitation. Given that pain is multifaceted and that the study delivers a multicomponent intervention designed to address functional impairment, we used a well-validated pain disability measure as an eligibility screener. Participants with a score of $\geq 7$ on the Roland Morris Disability Scale [15] were considered to meet the eligibility criterion of moderate 
functional impairment. Exclusion criteria consisted of severe medical conditions that would limit study participation (e.g., New York Heart class III or IV heart failure), active psychosis, moderate cognitive deficits, severe impairment of hearing or speech, active suicidal ideation, prior back surgery or pending surgery, current substance dependence, and current pregnancy or trying to become pregnant.

Informed consent was obtained in writing from every participant in the trial. Assessments were conducted either face-to-face or by telephone by a trained interviewer. This project was approved by the Indiana University Institutional Review Board and Roudebush VA Research and Development Committee.

\section{Measures}

\section{Posttraumatic Stress Disorder}

PTSD was assessed in two stages, first with a screening instrument and then with a validated self-report questionnaire. The Primary Care PTSD screen (PC-PTSD) [16] is a 4-item self-report measure developed to screen for PTSD in primary care and other medical settings. Represented in the items are the three cardinal symptom clusters of PTSD (i.e., re-experiencing, avoidance, and arousal). To optimize sensitivity, a low threshold was used to indicate a positive screen (i.e., at least one positive response was sufficient) for PTSD. Those who screened positive were subsequently administered the Posttraumatic Stress Disorder Checklist (PCL) [17]). The PCL is a 17 -item self-report questionnaire that assesses the presence and severity of PTSD symptoms. Scores range from 0 to 68 , with higher scores representing more severe posttraumatic stress symptoms. The PCL has been developed in three versions to assess posttraumatic responses to military trauma, a specific traumatic event, or any trauma. The study used the PCL-Civilian (PCL-C) version because it addresses the broadest range of possible events as the traumatic stressor. The PCL-C has demonstrated strong reliability and validity in multiple samples [17-18] and has good concurrent validity with the Clinician-Administered Posttraumatic Stress interview [19], the "gold standard" in diagnostic measurement of PTSD.

For categorization of participants with clinically significant PTSD symptoms, a cut point of $\geq 41$ was used. Recommended cut points have ranged from 31 [19] to 60 [20], and there remains lack of consensus regarding the best diagnostic threshold for the PCL-C [21-22]. The minimum possible score that corresponds with a Diagnostic and Statistical Manual of Mental Disorders-IV [23] diagnosis of PTSD is 41 and is thus considered clinically significant [17].

\section{Pain Characteristics}

The study team measured pain severity, disability, and interference with activities to understand Veterans' degree of pain and its impact on physical and general functioning. Pain severity was assessed with the Graded Chronic Pain Scale (GCPS) [24], a 7-item self-report instrument that invites respondents to rate their global pain on a scale of $0-100$, with higher scores representing more severe pain. The GCPS has demonstrated good internal consistency, test-retest reliability, and validity [25-26].

The Roland Morris Disability Questionnaire [15] is a 24-item self-report scale developed to measure painrelated disability among patients with low back pain. Each item is scored "yes" or "no"; total scores thus range from 0 to 24, where 24 represents greater disability due to pain. Psychometric properties of this scale are strong, and it has been shown to outperform other measures of physical functioning in chronic pain populations [27]. This instrument was initially developed to assess disability among patients with chronic low back pain but has since been validated among other nonmalignant pain samples [28-30]. It demonstrated good reliability (Cronbach alpha $=0.88$ ) with a sample of patients with chronic musculoskeletal pain [29-30].

The 7-item interference scale of the Brief Pain Inventory (BPI) [31] was used to measure the degree to which Veterans' pain interferes with various domains of their daily lives. The items assess the extent of pain interference with mood, physical activity, work, social activity, relations with others, sleep, and enjoyment of life. Item responses were summed and averaged. Interference scores range from 0 to 10 , with 10 indicating the most pain-related interference. The BPI has demonstrated strong psychometric properties and appears to be sensitive to changes in pain over time [32].

\section{Pain Cognitions}

Three different pain-specific sets of cognitions shown to be associated with pain outcomes were assessed. Pain catastrophizing, or the tendency to ruminate on pain, magnify pain sensations, or feel helpless 
about pain, was measured with the Pain Catastrophizing Scale (PCS) [14]. Scores range from 0 to 52, with higher scores representing more catastrophic thinking. The PCS is a 13-item self-report questionnaire with strong reliability and concurrent and discriminant validity [33].

Pain self-efficacy was measured with the Arthritis Self-Efficacy Scale [34], a 6-item self-report instrument designed to assess one's belief in personal ability to manage arthritis pain. The item scores were summed and averaged, providing a range from 0 to 10 , with higher scores representing greater confidence in one's ability to manage pain. This scale has shown good reliability and validity [35] and has been successfully used in other nonarthritis pain samples [36].

The study assessed pain centrality, a new construct that signifies the degree to which the experience of chronic pain is central to a respondent's life and identity [37]. The Centrality of Pain Scale [37] is 10-item selfreport measure with items such as "My pain defines who I am," "I think about pain all the time," and "My life revolves around my pain." Scores range from 10 to 50, with higher scores indicating more pain centrality. This new scale has shown promising psychometric properties, with excellent internal consistency and construct validity [37]. Centrality of pain is of particular interest given its potential for impacting pain outcomes [37]. The scale was developed following repeated clinical observations that patients appear to identify themselves strongly as "a pain patient" and view their pain as intractable. It is theorized that these beliefs might serve as a barrier to treatment response, and preliminary findings support this notion [37].

\section{Affective Distress}

Symptoms of depression and anxiety were measured with two different instruments: the Patient Health Questionnaire (PHQ-9) [38] and the Generalized Anxiety Disorder (GAD-7) instrument [39], respectively. The PHQ-9 is a widely used 9-item self-report measure of depression severity with excellent reliability and validity and good sensitivity and specificity for identifying depression diagnoses [40]. Scores range from 0 to 27, with higher scores representing more frequent depressive symptoms in the past 2 weeks. The GAD-7 is a 7-item self-report scale of anxiety symptom severity. The GAD-7 has demonstrated good reliability, criterion, construct, factorial, and procedural validity [41]. Scores range from 0 to 21, with higher scores indicating more frequent anxiety symptoms.

\section{Statistical Analysis}

The mean and standard deviation (SD) were calculated for continuous descriptive variables and outcome measures. Frequencies and percentages were calculated for categorical variables. Separate analyses were conducted to compare groups by PTSD status on the primary outcome variables (pain severity, pain-related disability, pain interference, pain catastrophizing, pain self-efficacy, pain centrality, depression, and anxiety). Two comparison groups were created with baseline data: those with comorbid PTSD and those without PTSD. Those who screened positive on the PC-PTSD and met a cut score of $\geq 41$ on the PCL-C were classified into the "PTSD" group. Those who screened negative on the PC-PTSD or screened positive but then scored below the PCL-C cutoff (41) were considered to be in the "no PTSD" group. Participants who screened negative on the PC-PTSD were not assessed with the PCL-C. Given the eligibility criteria for the ESCAPE clinical trial, participants in both groups experienced chronic musculoskeletal pain associated with at least moderate functional impairment.

To test for group differences (PTSD vs no PTSD), $t$ tests were conducted on the following dependent variables: pain severity, pain-related disability, pain interference, pain catastrophizing, pain self-efficacy, pain centrality, depression, and anxiety. The study team further expanded these univariate analyses with analysis of covariance (ANCOVA) models that included age, sex, race, income, and medical comorbidities as covariates to identify potential group differences after adjusting for these factors. The aforementioned eight dependent variables were included in these eight ANCOVA models. All statistical analyses were conducted with SAS version 9.3 (SAS Institute Inc; Cary, North Carolina).

\section{RESULTS}

\section{Participants}

The sample included 241 participants, whose ages ranged from 21 to $73 \mathrm{yr}$ old (mean $\pm \mathrm{SD}=36.7 \pm 10.3$ ). The ESCAPE sample was predominantly male $(n=213$, $88.4 \%)$, white $(n=185,77.7 \%)$, employed or in school ( $n=177,73.4 \%)$, and not comfortable with their current level of income $(n=153,63.5 \%)$. All participants had at least a high school education. Most participants had served in the Army $(n=160,66.4 \%)$ and had recently deployed to Iraq $(n=180,75.0 \%)$. Number of comorbid 
medical conditions ranged from 0 to 5 (mean $\pm \mathrm{SD}=0.95$ \pm 0.98). Participant demographic characteristics for the entire sample and by comparison group (i.e., PTSD vs no PTSD) are presented in Table 1. Of note, the only significant group difference was seen for income comfort level ("Would you say that you are comfortable with your household income, have just enough to make ends meet, or do not have enough to make ends meet?").

More than three-fourths of the sample (78.4\%) screened positive for PTSD, according to a sensitively set cutoff on the PC-PTSD. Of those who screened positive, 36.0 percent met the clinically significant PCL-C score of $\geq 41$. Those who screened positive and scored $\geq 41$ were categorized into the PTSD group ( $n=68,28.2 \%$ ). Those who screened negative or screened positive but scored $<41$ on the PCL-C $(n=173,71.8 \%)$ were classified into the no PTSD group.

\section{Group Differences in Pain Characteristics, Pain Cognitions, and Affective Distress}

\section{Unadjusted Group Differences}

Table 2 presents the results of univariate analyses. All tests yielded statistically significant group differences, with the PTSD group demonstrating greater pain severity, more pain-related disability, greater pain interference, more pain catastrophizing, lower pain selfefficacy, higher pain centrality, more depression, and more anxiety than the no PTSD group. On average, the PTSD group scored 8.5 points higher on pain severity (where scores range from 0 to 100), nearly 3 points higher on pain-related disability (where scores range from 0 to 24), 2 points higher on pain interference (where scores range from 0 to 10 ), nearly 10 points higher on pain catastrophizing (where scores range from 0 to 52 ), more than 1 point lower on pain self-efficacy (where

Table 1.

Overall sample characteristics and by posttraumatic stress disorder (PTSD) status.

\begin{tabular}{|c|c|c|c|}
\hline Characteristic & Total $(N=241)$ & PTSD $(n=68)$ & No PTSD $(n=173)$ \\
\hline$\overline{\text { Age, } \text { Mean } \pm \mathrm{SD}^{*}}$ & $36.72 \pm 10.25$ & $35.12 \pm 9.20$ & $37.35 \pm 10.59$ \\
\hline Sex: Male, $n(\%)^{\dagger}$ & $213(88.38)$ & $60(88.24)$ & $153(88.44)$ \\
\hline Race: White, $n(\%)^{\dagger}$ & $185(77.73)$ & $50(73.53)$ & $135(79.41)$ \\
\hline Income: Comfortable, $n(\%)^{\dagger}$ & $153(63.49)$ & $14+(20.59)$ & $74 *(42.77)$ \\
\hline Medical Comorbidities, Mean $\pm \mathrm{SD}^{*}$ & $0.95 \pm 0.98$ & $1.04 \pm 1.16$ & $0.91 \pm 0.90$ \\
\hline \multicolumn{4}{|c|}{$\begin{array}{l}\text { Note: PTSD }=\text { positive screen and PCL-C } \geq 41 \text {; No PTSD }=\text { ne } \\
{ }^{*} \text { Compared with two-sample } t \text {-test. } \\
{ }^{\dagger} \text { Analyzed with chi-square test. } \\
{ }^{\ddagger} p=0.001 \text { (only significant group difference at } p<0.05 \text { level). } \\
\text { PCL-C }=\text { Posttraumatic Stress Disorder Checklist-Civilian, SD }\end{array}$} \\
\hline
\end{tabular}

Table 2.

Pain and psychological variables by posttraumatic stress disorder (PTSD) status.

\begin{tabular}{|c|c|c|c|}
\hline Variable & PTSD $(n=68)$, Mean \pm SD & No PTSD $(n=173)$, Mean \pm SD & $t(239)$ \\
\hline \multicolumn{4}{|l|}{ Pain Characteristics } \\
\hline Pain Severity (GCPS) & $72.30 \pm 11.64$ & $63.83 \pm 13.76$ & $-4.5^{*}$ \\
\hline Pain-Related Disability (Roland) & $15.97 \pm 4.26$ & $13.06 \pm 4.32$ & $-4.7^{*}$ \\
\hline Pain Interference (BPI) & $6.88 \pm 1.87$ & $4.78 \pm 2.05$ & $-7.3^{*}$ \\
\hline \multicolumn{4}{|l|}{ Pain Cognitions } \\
\hline Pain Catastrophizing (PCS) & $28.59 \pm 12.20$ & $18.90 \pm 11.24$ & $-5.9^{*}$ \\
\hline \multicolumn{4}{|l|}{ Affective Distress } \\
\hline Depression (PHQ-9) & $16.32 \pm 4.50$ & $9.17 \pm 5.14$ & $-10.1^{*}$ \\
\hline Anxiety (GAD-7) & $13.79 \pm 4.04$ & $6.85 \pm 4.31$ & $-11.5^{*}$ \\
\hline
\end{tabular}


scores range from 0 to 10), more than 6 points higher on pain centrality (where scores range from 10 to 50), and approximately 7 points higher on both depression (where scores range from 0 to 27 ) and anxiety (where scores range from 0 to 21 ).

\section{Adjusted Group Differences}

Separate ANCOVA models were created for the eight dependent variables: pain severity, pain-related disability, pain interference, pain catastrophizing, pain self-efficacy, pain centrality, depression, and anxiety. Model results were consistent with the univariate findings; for all variables, there were statistically significant differences between groups, with poorer scores for those with PTSD than for those without. Table 3 presents ANCOVA results related to pain severity. After adjusting for covariates (i.e., age, sex, race, income, medical comorbidities), the between-group differences remained significant, with the PTSD group scoring nearly 8 points higher on pain severity than the no PTSD group. Table 4 summarizes ANCOVA results of pain centrality as representative of assessed pain cognitions. Statistically significant betweengroup differences emerged, with the PTSD group reporting greater pain centrality than the no PTSD group. Table 5 shows the results from the ANCOVA model that exam- ined group differences on depression. Group differences are notable; those with PTSD scored nearly 7 points higher on the PHQ-9 than those without PTSD.

\section{DISCUSSION}

The results of this study supported the hypothesis that Veterans with comorbid chronic pain and PTSD, compared with those with pain only, would report a physical and emotional experience that is significantly more intense and disabling. These findings suggest that pain is more severe, is associated with more disability, and interferes more with a Veteran's life when PTSD accompanies chronic pain. Additionally, pain cognitions (i.e., how a person thinks about pain and about him- or herself in the context of pain) appear to differ when PTSD is present. For instance, those with comorbid PTSD demonstrated more catastrophic thinking about their pain, had less confidence in their ability to manage their pain, and viewed pain as more central to their lives as compared with those with chronic pain only. Furthermore, Veterans with comorbid pain and PTSD reported more depression and anxiety symptoms than those with pain only.

Table 3.

Relationship between posttraumatic stress disorder (PTSD) status and pain severity.

\begin{tabular}{lcccc}
\hline \multicolumn{1}{c}{ Source } & Beta Estimate & Sum of Squares* & $\boldsymbol{F}$ & $\boldsymbol{p}$-Value \\
\hline Age (continuous) & -0.08 & 135.17 & 0.79 & 0.38 \\
Sex (female vs male) & 4.72 & 538.98 & 3.15 & 0.08 \\
Race (nonwhite vs white) & 2.53 & 243.27 & 1.42 & 0.23 \\
Income (comfortable vs not) & -0.18 & 1.58 & 0.01 & 0.92 \\
Medical Comorbidities (continuous) & 0.59 & 64.57 & 0.38 & 0.54 \\
PTSD Status (yes vs no) & 7.93 & $2,887.88$ & 16.86 & $<0.001$ \\
\hline
\end{tabular}

Note: Analysis of covariance full model: $F(6,231)=4.32, p<0.001$.

*Equivalent to mean square, degrees of freedom $=1$.

Table 4.

Relationship between posttraumatic stress disorder (PTSD) status and centrality of pain.

\begin{tabular}{lcccc}
\hline \multicolumn{1}{c}{ Source } & Beta Estimate & Sum of Squares & $\boldsymbol{F}$ & $\boldsymbol{p}$-Value \\
\hline Age (continuous) & -0.11 & 217.31 & 3.95 & 0.05 \\
Sex (female vs male) & 1.21 & 35.58 & 0.65 & 0.42 \\
Race (nonwhite vs white) & -2.42 & 222.29 & 4.05 & 0.05 \\
Income (comfortable vs not) & -1.38 & 93.51 & 1.70 & 0.19 \\
Medical Comorbidities (continuous) & 0.68 & 84.39 & 0.22 \\
PTSD Status (yes vs no) & 5.74 & $1,509.97$ & 27.48 & $<0.001$ \\
\hline
\end{tabular}

Note: Analysis of covariance full model: $F(6,231)=7.60, p<0.001$.

*Equivalent to mean square, degrees of freedom $=1$. 
Table 5.

Relationship between posttraumatic stress disorder (PTSD) status and depression.

\begin{tabular}{lcccc}
\multicolumn{1}{c}{ Source } & Beta Estimate & Sum of Squares* & $\boldsymbol{F}$ & $\boldsymbol{p}$-Value \\
\hline Age (continuous) & -0.05 & 54.53 & 2.27 & 0.13 \\
Sex (female vs male) & 1.03 & 25.38 & 1.06 & 0.31 \\
Race (nonwhite vs white) & 0.09 & 0.33 & 0.01 & 0.91 \\
Income (comfortable vs not) & -1.06 & 55.49 & 2.31 & 0.13 \\
Medical Comorbidities (continuous) & 0.73 & 98.49 & & \\
PTSD Status (yes vs no) & 6.76 & $2,094.35$ & & \\
Note: Analysis of covariance full model: $F(6,231)=19.11, p<0.001$. & & & \\
*Equivalent to mean square, degrees of freedom $=1$. & & & \\
\hline \hline
\end{tabular}

The high rate of comorbidity between chronic pain and PTSD has been well documented [5,9,42-44], and results from this study are consistent with these prior epidemiologic studies that have identified high prevalence rates of chronic pain and PTSD. Previous literature has demonstrated associations between PTSD and intensified pain severity, disability, and interference [45-47]; however, at least one study did not corroborate this finding [4]. Results from the current study contribute further evidence to support the relationship between PTSD comorbidity and intensified pain features. Additionally, this study extends previous work to a growing population of U.S. Veterans returning from wars in Iraq and Afghanistan, a group that is entering the VA healthcare system at high rates with significant need for healthcare services $[7,9,48]$.

This study expands upon previous work in painPTSD comorbidity by considering pain-related cognitive patterns; although cognition has been shown to be relevant to chronic pain [49-50], this has not been fully examined in the context of PTSD comorbidity. Specifically, pain catastrophizing, self-efficacy, and centrality were examined. Pain catastrophizing has been previously linked with higher pain intensity and greater disability, and reductions of catastrophic thinking are associated with positive pain treatment outcomes [51-52]. The study team considers it clinically meaningful, then, to find significantly greater pain catastrophizing among those who also experience PTSD. Alschuler and Otis also found more pain catastrophizing among Veterans with pain and PTSD compared with those with pain only [13], though their measurement tool omitted the magnification and rumination components of catastrophizing. In the current sample, the pain-PTSD comorbidity group demonstrated greater catastrophizing than those with pain alone, even with the use of a more comprehensive measure of catastrophizing.
Pain self-efficacy is an important cognition to consider in association with pain outcomes. It represents a sense of confidence in being able to take action to manage one's own pain. Previous literature has demonstrated associations between higher pain self-efficacy and greater control over pain, better prognosis [53-54], and improved response to pain treatment [55-56]. Current results suggest that those with PTSD have lower pain self-efficacy than those without, which may lead to downstream effects such as less effective adoption of skills to manage pain and comparatively worse treatment outcomes.

Centrality of pain is a newer construct in the chronic pain literature and is conceptualized as the degree to which individuals view pain as a core component of their life and/or identity. This is an intriguing concept, given clinical observations that patients who strongly identify with their pain tend to be less open to biopsychosocial explanations or interventions. It is conceptually similar to the idea of cognitive fusion from the acceptance and commitment therapy literature, wherein an individual may be attached to a thought (e.g., "I am always in pain") that influences thinking about behavior (e.g., "I cannot attend this event because I am always in pain") and increases experiential avoidance [57]. Centrality of pain may represent a particular type of cognitive fusion in that it describes thoughts specifically about chronic pain. The only published study thus far on centrality of pain [37] demonstrated a relationship between higher centrality and lower physical and mental health functioning. Results from the current study yielded, among OIF/OEF Veterans with both chronic pain and PTSD, higher scores of pain centrality than those without PTSD. Thus, Veterans with PTSD viewed their pain as more elemental to their lives than Veterans without PTSD. It is noteworthy that it is specifically the pain that is viewed as more central among the comorbid PTSD group and merits exploring the direction of influence between PTSD and pain centrality. 
These results can be interpreted in a number of ways. Although this study's cross-sectional design precludes causal inferences, one plausible interpretation of these data is that the presence of posttraumatic stress symptoms amplifies the experience of chronic pain, and/or perhaps vice versa. A recent longitudinal study uncovered the complex nature of depression and chronic pain, detailing how the two reciprocally serve to exacerbate and maintain one another [58]. It would be logical to suppose that PTSD and chronic pain may follow a similar pattern. Indeed, the mutual maintenance model [59], one theoretical model of PTSD-chronic pain comorbidity, proposes that the two conditions contribute to one another in ways that serve to perpetuate one other. The maladaptive cognitive patterns identified in this study may serve as one mechanism that the two conditions influence one another, though specific testing of this hypothesis is needed. Further empirical investigation is warranted to validate the mutual maintenance model, but it is useful in considering how chronic pain and PTSD might interrelate and contribute to one another.

Another possible framework for understanding these results may be found in the shared vulnerability model [60], which posits anxiety sensitivity as a predisposing factor for developing PTSD following a traumatic event and chronic pain following a physical injury. The triple vulnerability model [61] further refines this concept to include a sense of lacking control as an integral factor in the development of chronic pain. The feeling of not being in control is a significant clinical feature of PTSD as well, and perhaps it is this aspect of PTSD that leads to the intensified pain cognitions found in these results. There is preliminary support for this notion in Alschuler and Otis' recent study that found lower sense of control over pain among Veterans with pain and PTSD compared with those with pain alone [13].

This study's limitations include its cross-sectional design, though this study team is finalizing a longitudinal data set that will allow for longitudinal analyses of these important variables. Although this is a single-site study and it is unknown whether these findings would generalize to Veterans of other eras, to civilian samples, or to those who are not seeking treatment for chronic pain, it is one of the largest pain treatment studies with OIF/OEF Veterans and provides significant insights into that population. PTSD was not assessed with the gold standard diagnostic interview, the Clinician-Administered PTSD Scale [62], and a highly sensitive cut score of the PCL-C was chosen, which affects the specificity of PTSD diagnosis. The study may be further limited by lack of specific information about the pain origin or traumatic event, which may be relevant particularly when the onset of chronic pain co-occurred with the index trauma. The results would be confounded, for example, if those Veterans with PTSD had sustained more severe physical injuries than those without, which would explain higher pain severity and disability among the comorbidity group.

Despite the noted limitations, these findings have important implications clinically, empirically, and theoretically. When treating a Veteran with chronic pain, regardless of the discipline or modality of treatment, it is important to assess for PTSD or to be aware of the Veteran's comorbid PTSD. Veterans who experience PTSD are likely to experience more intense and disabling pain, more maladaptive thought patterns, and more affective distress, and a provider may need to tailor pain treatment for the patient with comorbid PTSD. At least one study has suggested that treating PTSD may beneficially affect the experience of chronic pain [5]. This highlights the importance of assessing PTSD symptoms when treating Veterans with chronic pain. These findings lend support to recommendations to use cognitive therapy techniques, such as those incorporated into cognitive-behavioral therapy, in order to target specific pain-related thoughts and to restructure them into more adaptive patterns of thinking.

Although this study furthers the understanding of the complex nature of chronic pain and PTSD comorbidity, unanswered questions remain. Future research should examine the longitudinal nature of this comorbidity to further elucidate the chronic pain differences between those with and without PTSD. It is important to investigate whether PTSD symptoms serve as a barrier to treatment response for someone undergoing psychological or multidisciplinary treatment for chronic pain. Additionally, this study highlights the importance of pain cognitions and future research should examine cognitive factors in greater depth.

In developing a better understanding of how individuals experience comorbid chronic pain and PTSD, the ultimate hope is to improve care and treatment of those dually experiencing both physical and emotional pain. 


\section{CONCLUSIONS}

These results suggest a worse overall experience of chronic pain for the Veteran also living with PTSD, pointing to comparatively increased pain severity, disability, pain-related interference, specific thought patterns related to pain, and emotional distress. These findings help to understand the complex relationship between chronic pain and PTSD and serve to inform future clinical trials. In particular, the three cognitive patterns identified in this study as associated with painPTSD comorbidity (i.e., pain catastrophizing, pain centrality, pain self-efficacy) should be important targets of treatment within cognitive-behavioral therapy with Veterans experiencing both conditions.

\section{ACKNOWLEDGMENTS}

\section{Author Contributions:}

Study concept and design: D. C. Ang, M. J. Bair, S. D. Outcalt, J. Wu, $\mathrm{Z}$. Yu.

Acquisition, analysis, and interpretation of data: D. C. Ang,

M. J. Bair, S. D. Outcalt, C. Sargent, J. Wu, Z. Yu.

Drafting of manuscript: D. C. Ang, M. J. Bair, S. D. Outcalt, J. Wu, Z. Yu.

Substantive review and revision of manuscript: D. C. Ang, M. J. Bair, S. D. Outcalt, C. Sargent, J. Wu, Z. Yu.

Statistical analysis: J. Wu, Z. Yu.

Study supervision: M. J. Bair, C. Sargent.

Financial Disclosure: The authors have declared that no competing interests exist.

Funding/Support: This material was based on work supported by a Department of Veterans Affairs (VA) Rehabilitation Research and Development Merit Review Award (grant F44371). The first author was financially supported during this project by a VA Health Services Research and Development Associated Health Fellowship.

Institutional Review: Before the start of this study, approval was obtained from the Indiana University Institutional Review Board and the Roudebush VA Medical Center Research and Development Review Committee. Informed consent was obtained in writing from every participant in the trial.

Participant Follow-Up: The authors do not plan to inform participants of the publication of this study.

\section{REFERENCES}

1. Kroenke K, Koslowe P, Roy M. Symptoms in 18,495 Persian Gulf War veterans. Latency of onset and lack of association with self-reported exposures. J Occup Environ Med. 1998;40(6):520-28. [PMID:9636932] http://dx.doi.org/10.1097/00043764-199806000-00004
2. Dohrenwend BP, Turner JB, Turse NA, Adams BG, Koenen KC, Marshall R. The psychological risks of Vietnam for U.S. veterans: A revisit with new data and methods. Science. 2006;313(5789):979-82. [PMID:16917066] http://dx.doi.org/10.1126/science.1128944

3. Kessler RC, Berglund PA, Demler O, Jin R, Merikangas $\mathrm{KR}$, Walters EE. Lifetime prevalence and age-of-onset distributions of DSM-IV disorders in the National Comorbidity Survey Replication. Arch Gen Psychiatry. 2005; 62(6):593-602. [PMID:15939837] http://dx.doi.org/10.1001/archpsyc.62.6.593

4. Otis JD, Gregor K, Hardway C, Morrison J, Scioli E, Sanderson K. An examination of the co-morbidity between chronic pain and posttraumatic stress disorder on U.S. Veterans. Psychol Serv. 2010;7:126-35. http://dx.doi.org/10.1037/a0020512

5. Shipherd JC, Keyes M, Jovanovic T, Ready DJ, Baltzell D, Worley V, Gordon-Brown V, Hayslett C, Duncan E. Veterans seeking treatment for posttraumatic stress disorder: What about comorbid chronic pain? J Rehabil Res Dev. 2007;44(2):153-66. [PMID:17551870] http://dx.doi.org/10.1682/JRRD.2006.06.0065

6. Kessler RC, Sonnega A, Bromet E, Hughes M, Nelson CB. Posttraumatic stress disorder in the National Comorbidity Survey. Arch Gen Psychiatry. 1995;52(12):1048-60. [PMID:7492257] http://dx.doi.org/10.1001/archpsyc.1995.03950240066012

7. Clark ME, Bair MJ, Buckenmaier CC 3rd, Gironda RJ, Walker RL. Pain and combat injuries in soldiers returning from Operations Enduring Freedom and Iraqi Freedom: Implications for research and practice. J Rehabil Res Dev. 2007;44(2):179-94. [PMID:17551872] http://dx.doi.org/10.1682/JRRD.2006.05.0057

8. Gironda RJ, Clark ME, Massengale JP, Walker RL. Pain among veterans of Operations Enduring Freedom and Iraqi Freedom. Pain Med. 2006;7(4):339-43. [PMID:16898945] http://dx.doi.org/10.1111/j.1526-4637.2006.00146.x

9. Helmer DA, Chandler HK, Quigley KS, Blatt M, Teichman R, Lange G. Chronic widespread pain, mental health, and physical role function in OEF/OIF veterans. Pain Med. 2009;10(7):1174-82. [PMID:19818029] http://dx.doi.org/10.1111/j.1526-4637.2009.00723.x

10. Kalra R, Clark ME, Schotten J, Murphy JL, Clements KL. Managing pain among returning service members. Fed Pract. 2008;25:36-45.

11. Lew HL, Otis JD, Tun C, Kerns RD, Clark ME, Cifu DX. Prevalence of chronic pain, posttraumatic stress disorder, and persistent postconcussive symptoms in OIF/OEF veterans: Polytrauma clinical triad. J Rehabil Res Dev. 2009; 46(6):697-702. [PMID:20104399] http://dx.doi.org/10.1682/JRRD.2009.01.0006 
12. Tanielian T, Jaycox LH. Invisible wounds of war: Psychological and cognitive injuries, their consequences, and services to assist recovery. Santa Monica (CA): The RAND Center for Military Health Policy Research; 2008.

13. Alschuler KN, Otis JD. Coping strategies and beliefs about pain in veterans with comorbid chronic pain and significant levels of posttraumatic stress disorder symptoms. Eur J Pain. 2012;16(2):312-19. [PMID:22323383] http://dx.doi.org/10.1016/j.ejpain.2011.06.010

14. Sullivan MJ, Bishop SR, Pivik J. The Pain Catastrophizing Scale: Development and validation. Psychol Assess. 1995; 7:524-32. http://dx.doi.org/10.1037/1040-3590.7.4.524

15. Roland MO, Morris RW. A study of the natural history of back pain. Part I: Development of a reliable and sensitive measure of disability in low-back pain. Spine. 1983;8(2): 141-44. [PMID:6222486] http://dx.doi.org/10.1097/00007632-198303000-00004

16. Prins A, Ouimette P, Kimerling R, Cameron RP, Hugelshofer DS, Shaw-Hegwer J, Thrailkill A, Gusman FD, Sheikh JI. The primary care PTSD screen (PC-PTSD): Development and operating characteristics. Prim Care Psychiatry. 2004;9:9-14. http://dx.doi.org/10.1185/135525703125002360

17. Blanchard EB, Jones-Alexander J, Buckley TC, Forneris CA. Psychometric properties of the PTSD Checklist (PCL). Behav Res Ther. 1996;34(8):669-73. [PMID:8870294] http://dx.doi.org/10.1016/0005-7967(96)00033-2

18. Conybeare D, Behar E, Solomon A, Newman MG, Borkovec TD. The PTSD Checklist-Civilian Version: reliability, validity, and factor structure in a nonclinical sample. J Clin Psychol. 2012;68(6):699-713. [PMID:22517497] http://dx.doi.org/10.1002/jclp.21845

19. Yeager DE, Magruder KM, Knapp RG, Nicholas JS, Frueh BC. Performance characteristics of the posttraumatic stress disorder checklist and SPAN in Veterans Affairs primary care settings. Gen Hosp Psychiatry. 2007;29(4):294-301. [PMID:17591505] http://dx.doi.org/10.1016/j.genhosppsych.2007.03.004

20. Keen SM, Kutter CJ, Niles BL, Krinsley KE. Psychometric properties of PTSD Checklist in sample of male veterans. J Rehabil Res Dev. 2008;45(3):465-74. [PMID:18629754] http://dx.doi.org/10.1682/JRRD.2007.09.0138

21. McDonald SD, Calhoun PS. The diagnostic accuracy of the PTSD checklist: A critical review. Clin Psychol Rev. 2010;30(8):976-87. [PMID:20705376] http://dx.doi.org/10.1016/j.cpr.2010.06.012

22. Ruggiero KJ, Del Ben K, Scotti JR, Rabalais AE. Psychometric properties of the PTSD Checklist-Civilian Version. J Trauma Stress. 2003;16(5):495-502. [PMID:14584634] http://dx.doi.org/10.1023/A:1025714729117

23. American Psychiatric Association. Diagnostic and statistical manual of mental disorders-Text revision, 4th edition. Washington (DC): American Psychiatric Association; 2000.
24. Von Korff M, Dworkin SF, Le Resche L. Graded chronic pain status: An epidemiologic evaluation. Pain. 1990; 40(3):279-91. [PMID:2326094]

http://dx.doi.org/10.1016/0304-3959(90)91125-3

25. Dworkin SF, Von Korff M, Whitney CW, LeResche L, Dicker BG, Barlow W. Measurement of characteristic pain intensity in field research. Pain Suppl. 1990;41:S290. http://dx.doi.org/10.1016/0304-3959(90)92696-N

26. Von Korff M. Epidemiological and survey methods: Assessment of chronic pain. In: Turk D, Melzack R, editors. Handbook of pain assessment. New York (NY): The Guilford Press; 2001. p. 603-18.

27. Ostelo RW, de Vet HC, Knol DL, van den Brandt PA. 24item Roland-Morris Disability Questionnaire was preferred out of six functional status questionnaires for post-lumbar disc surgery. J Clin Epidemiol. 2004;57(3):268-76.

[PMID:15066687]

http://dx.doi.org/10.1016/j.jclinepi.2003.09.005

28. Jensen MP, Strom SE, Turner JA, Romano JM. Validity of the Sickness Impact Profile Roland scale as a measure of dysfunction in chronic pain patients. Pain. 1992;50(2):157-62. [PMID:1408311] http://dx.doi.org/10.1016/0304-3959(92)90156-6

29. Kroenke K, Bair M, Damush T, Hoke S, Nicholas G, Kempf C, Huffman M, Wu J, Sutherland J. Stepped Care for Affective Disorders and Musculoskeletal Pain (SCAMP) study: Design and practical implications of an intervention for comorbid pain and depression. Gen Hosp Psych. 2007;29(6):506-17. [PMID:18022044] http://dx.doi.org/10.1016/j.genhosppsych.2007.08.005

30. Kroenke K, Bair MJ, Damush TM, Wu J, Hoke S, Sutherland $\mathrm{JM}, \mathrm{Tu} \mathrm{W}$. Optimized antidepressant therapy and pain self-management in primary care patients with musculoskeletal pain and depression: A randomized controlled trial. JAMA. 2009;301:2099-110. [PMID:19470987] http://dx.doi.org/10.1001/jama.2009.723

31. Cleeland CS, Ryan KM. Pain assessment: Global use of the Brief Pain Inventory. Ann Acad Med Singapore. 1994; 23(2):129-38. [PMID:8080219]

32. Tan G, Jensen MP, Thornby JI, Shanti BF. Validation of the Brief Pain Inventory for chronic nonmalignant pain. J Pain. 2004;5(2):133-37. [PMID:15042521] http://dx.doi.org/10.1016/j.jpain.2003.12.005

33. Osman A, Barrios FX, Kopper BA, Hauptmann W, Jones J, O'Neill E. Factor structure, reliability, and validity of the Pain Catastrophizing Scale. J Behav Med. 1997;20(6):589-605. [PMID:9429990] http://dx.doi.org/10.1023/A:1025570508954

34. Lorig K, Chastain RL, Ung E, Shoor S, Holman HR. Development and evaluation of a scale to measure perceived self-efficacy in people with arthritis. Arthritis Rheum. 1989;32(1):37-44. [PMID:2912463] http://dx.doi.org/10.1002/anr.1780320107 
35. Barlow JH, Williams RB, Wright C. The Arthritis SelfEfficacy Scale in a UK context. Psychol Health Med. 1997;2:3-17.

http://dx.doi.org/10.1080/13548509708400556

36. Damush TM, Weinberger M, Perkins SM, Rao JK, Tierney WM, Qi R, Clark DO. Randomized trial of a self-management program for primary care patients with acute low back pain: Short-term effects. Arthritis Rheum. 2003; 49(2):179-86. [PMID:12687508] http://dx.doi.org/10.1002/art.10995

37. Nicolaidis C, Chianello T, Gerrity M. Development and preliminary psychometric testing of the centrality of pain scale. Pain Med. 2011;12(4):612-17. [PMID:21392248] http://dx.doi.org/10.1111/j.1526-4637.2011.01072.x

38. Kroenke K, Spitzer RL, Williams JB. The PHQ-9: Validity of a brief depression severity measure. J Gen Intern Med. 2001;16(9):606-13. [PMID:11556941] http://dx.doi.org/10.1046/j.1525-1497.2001.016009606.x

39. Spitzer RL, Kroenke K, Williams JB. Validation and utility of a self-report version of PRIME-MD: The PHQ primary care study. Primary Care Evaluation of Mental Disorders. Patient Health Questionnaire. JAMA. 1999;282(18):1737-44. [PMID:10568646] http://dx.doi.org/10.1001/jama.282.18.1737

40. Kroenke K, Spitzer RL, Williams JB, Löwe B. The Patient Health Questionnaire Somatic, Anxiety, and Depressive Symptom Scales: A systematic review. Gen Hosp Psychiatry. 2010;32(4):345-59. [PMID:20633738]

41. Spitzer RL, Kroenke K, Williams JB, Löwe B. A brief measure for assessing generalized anxiety disorder: The GAD-7. Arch Intern Med. 2006;166(10):1092-97. [PMID:16717171] http://dx.doi.org/10.1001/archinte.166.10.1092

42. Asmundson GJ, Norton GR, Allerdings MD, Norton PJ, Larsen DK. Posttraumatic stress disorder and work-related injury. J Anxiety Disord. 1998;12(1):57-69. [PMID:9549609] http://dx.doi.org/10.1016/S0887-6185(97)00049-2

43. Beckham JC, Crawford AL, Feldman ME, Kirby AC, Hertzberg MA, Davidson JR, Moore SD. Chronic posttraumatic stress disorder and chronic pain in Vietnam combat veterans. J Psychosom Res. 1997;43(4):379-89.

[PMID:9330237]

http://dx.doi.org/10.1016/S0022-3999(97)00129-3

44. Villano CL, Rosenblum A, Magura S, Fong C, Cleland C, Betzler TF. Prevalence and correlates of posttraumatic stress disorder and chronic severe pain in psychiatric outpatients. J Rehabil Res Dev. 2007;44(2):167-78.

[PMID:17551871]

http://dx.doi.org/10.1682/JRRD.2006.05.0052

45. Geisser ME, Roth RS, Bachman JE, Eckert TA. The relationship between symptoms of post-traumatic stress disor- der and pain, affective disturbance and disability among patients with accident and non-accident related pain. Pain. 1996;66(2-3):207-14. [PMID:8880842]

http://dx.doi.org/10.1016/0304-3959(96)03038-2

46. Sherman JJ, Turk DC, Okifuji A. Prevalence and impact of posttraumatic stress disorder-like symptoms on patients with fibromyalgia syndrome. Clin J Pain. 2000;16(2):127-34. [PMID:10870725] http://dx.doi.org/10.1097/00002508-200006000-00006

47. Turk DC, Okifuji A. Perception of traumatic onset, compensation status, and physical findings: Impact on pain severity, emotional distress, and disability in chronic pain patients. J Behav Med. 1996;19(5):435-53.

[PMID:8904727] http://dx.doi.org/10.1007/BF01857677

48. Seal KH, Shi Y, Cohen G, Cohen BE, Maguen S, Krebs EE, Neylan TC. Association of mental health disorders with prescription opioids and high-risk opioid use in US veterans of Iraq and Afghanistan. JAMA. 2012;307(9): 940-47. [PMID:22396516] http://dx.doi.org/10.1001/jama.2012.234

49. Jensen MP, Turner JA, Romano JM. Changes after multidisciplinary pain treatment in patient pain beliefs and coping are associated with concurrent changes in patient functioning. Pain. 2007;131(1-2):38-47.

[PMID: 17250963]

http://dx.doi.org/10.1016/j.pain.2006.12.007

50. Tan G, Teo I, Anderson KO, Jensen MP. Adaptive versus maladaptive coping and beliefs and their relation to chronic pain adjustment. Clin J Pain. 2011;27(9):769-74.

[PMID:21593665]

http://dx.doi.org/10.1097/AJP.0b013e31821d8f5a

51. Burns JW, Kubilus A, Bruehl S, Harden RN, Lofland K. Do changes in cognitive factors influence outcome following multidisciplinary treatment for chronic pain? A crosslagged panel analysis. J Consult Clin Psychol. 2003;71(1): 81-91. [PMID:12602428] http://dx.doi.org/10.1037/0022-006X.71.1.81

52. Sullivan MJ, Thorn B, Haythornthwaite JA, Keefe F, Martin M, Bradley LA, Lefebvre JC. Theoretical perspectives on the relation between catastrophizing and pain. Clin $\mathrm{J}$ Pain. 2001;17(1):52-64. [PMID:11289089] http://dx.doi.org/10.1097/00002508-200103000-00008

53. Foster NE, Thomas E, Bishop A, Dunn KM, Main CJ. Distinctiveness of psychological obstacles to recovery in low back pain patients in primary care. Pain. 2010;148(3):398-406. [PMID:20022697]

http://dx.doi.org/10.1016/j.pain.2009.11.002

54. Lorig K, Holman HR. Long-term outcomes of an arthritis self-management study: Effects of reinforcement efforts. Soc Sci Med. 1989;29(2):221-24. [PMID:2665110] http://dx.doi.org/10.1016/0277-9536(89)90170-6 
55. O'Leary A, Shoor S, Lorig K, Holman HR. A cognitivebehavioral treatment for rheumatoid arthritis. Health Psychol. 1988;7(6):527-44. [PMID:3063517]

http://dx.doi.org/10.1037/0278-6133.7.6.527

56. Turk DC, Okifuji A. Psychological factors in chronic pain: Evolution and revolution. J Consult Clin Psychol. 2002;

70(3):678-90. [PMID:12090376] http://dx.doi.org/10.1037/0022-006X.70.3.678

57. Hayes SC, Strosahl KD, Bunting K, Twohig M, Wilson $\mathrm{KG}$. What is acceptance and commitment therapy? In: Hayes CS, Strosahl KD, editors. A practical guide to acceptance and commitment therapy. New York (NY): Springer; 2004. p. 1-30.

58. Kroenke K, Wu J, Bair MJ, Krebs EE, Damush TM, Tu W. Reciprocal relationship between pain and depression: a 12month longitudinal analysis in primary care. J Pain. 2011; 12(9):964-73. [PMID:21680251] http://dx.doi.org/10.1016/j.jpain.2011.03.003

59. Sharp TJ, Harvey AG. Chronic pain and posttraumatic stress disorder: Mutual maintenance? Clin Psychol Rev. 2001;21(6):857-77. [PMID:11497210] http://dx.doi.org/10.1016/S0272-7358(00)00071-4

60. Asmundson GJ, Coons MJ, Taylor S, Katz J. PTSD and the experience of pain: Research and clinical implications of shared vulnerability and mutual maintenance models. Can J Psychiatry. 2002;47(10):930-37. [PMID:12553128]
61. Otis JD, Keane TM, Kerns RD. An examination of the relationship between chronic pain and post-traumatic stress disorder. J Rehabil Res Dev. 2003;40(5):397-405.

[PMID:15080224]

http://dx.doi.org/10.1682/JRRD.2003.09.0397

62. Blake DD, Weathers FW, Nagy LM, Kaloupek D, Klauminzer G, Charney DS, Keane TM, Buckley TC. ClinicianAdministered PTSD Scale (CAPS) instruction manual. Boston (MA): National Center for PTSD; 2000.

Submitted for publication June 6, 2013. Accepted in revised form December 16, 2013.

This article and any supplemental material should be cited as follows:

Outcalt SD, Ang DC, Wu J, Sargent C, Yu Z, Bair MJ. Pain experience of Iraq and Afghanistan Veterans with comorbid chronic pain and posttraumatic stress. J Rehabil Res Dev. 2014;51(4):559-70.

http://dx.doi.org/10.1682/JRRD.2013.06.0134

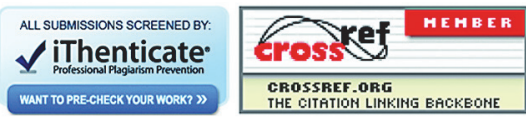

